\title{
A Combination of Visible-Light Organophotoredox Catalysis and Asym- metric Organocatalysis for the Enantioselective Mannich Reaction of Dihydroquinoxalinones with Ketones.
}

\author{
Jaume Rostoll-Berenguer, ${ }^{\mathrm{a}}$ Gonzalo Blay, ${ }^{\mathrm{a}}$ M. Carmen Muñoz, ${ }^{\mathrm{b}}$ José R. Pedro, ${ }^{\mathrm{a} *}$ Carlos Vila ${ }^{\mathrm{a} *}$ \\ ${ }^{a}$ Departament de Química Orgànica, Facultat de Química, Universitat de València, Dr. Moliner 50, 46100 Burjassot, Valèn- \\ cia (Spain). E-mail: jose.r.pedro@uv.es, carlos.vila@uv.es, \\ ${ }^{b}$ Departament de Física Aplicada, Universitat Politècnica de València, Camino de Vera s/n, 46022 València (Spain). \\ Supporting Information Placeholder
}

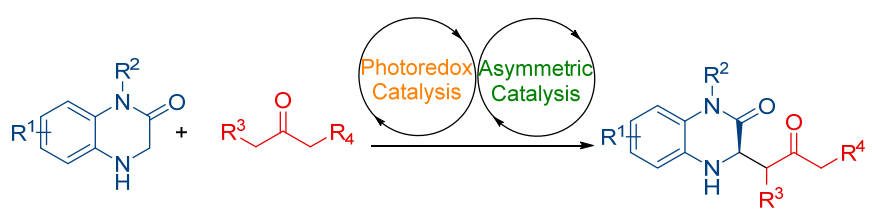

\begin{abstract}
An enantioselective photooxidative Mannich reaction of dihydroquinoxalinones with ketones by the merger of organophotoredox and asymmetric organocatalysis is described. This protocol features a very mild reaction conditions using simple and cheap catalysts (Eosin Y and (S)-Proline) for the synthesis of chiral quinoxaline derivatives with good to high yields (up to 94\%) and excellent enantioselectivities (up to $99 \%$ ee).
\end{abstract}

The employment of visible-light photoredox catalysis have become a hot topic in synthetic chemistry in the last decade, due to its significant advantages such as low cost, safe, renewable, abundant, and environmentally friendliness. ${ }^{1,2}$ On the other hand, control of chirality is one of the guiding principles in the chemical community over the last decades. One of the main objectives of the organic chemistry is exploit the full potential of synthetic chemistry to create and control chiral structures with different types of functions. ${ }^{3}$ In this context, asymmetric catalysis provides vast opportunities for an economical and efficient access to chiral compounds in enantiomerically pure form. ${ }^{4}$ Therefore, interfacing visible-light photochemical activation with asymmetric catalysis have provided new opportunities for the development of synthetic methods for efficient, convenient and green synthesis of non-racemic chiral molecules. ${ }^{5}$ In the last years, several examples of the combination of visible-light photoredox catalysts and organocatalysts have been described for the $\alpha$ - and $\beta$-functionalization of carbonyl compounds ${ }^{6}$ and for the $\mathrm{C}\left(\mathrm{sp}^{3}\right)-\mathrm{H} \alpha$ - functionalization of amines. ${ }^{7}$

Scheme 1. Enantioselective Photooxidative Mannich Reaction.

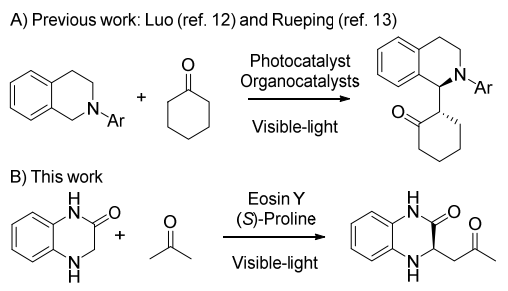

The enantioselective synthesis of chiral amines is, generally, a remarkable research area owing to the importance of chiral nitrogen-containing compounds for medicinal, pharmaceutical and agrochemical chemistry. ${ }^{8}$ In this context, since the pioneering report of List, ${ }^{9}$ the organocatalytic asymmetric Mannich reaction represents a powerful methodology for the synthesis of chiral amines..$^{10}$ Besides, the enantioselective oxidative Mannich reaction where $\mathrm{C}\left(\mathrm{sp}^{3}\right)-\mathrm{H} \alpha$-functionalization of amines with carbonyl compounds have been described recently. ${ }^{[11]}$ However, only two examples of the combination of visible-light photoredox catalysts and asymmetric catalysis for the oxidative Mannich reaction of amines (tetrahydroisoquinolines) and cyclic ketones have been described by Luo ${ }^{12}$ and Rueping, ${ }^{13}$ independently (Scheme 1). Therefore, our attention is focused on developing a suitable catalytic system for accomplishing the enantioselective $\mathrm{C}\left(\mathrm{sp}^{3}\right)$ - $\mathrm{H} \alpha$-functionalization of other amines different from tetrahydroisoquinolines. In particular, dihydroquinoxalinones constitute a prevailing scaffold frequently found in many biologically active natural and synthetic products (Figure 1). Many examples are used as pharmaceuticals, including antiviral compounds, used for the treatment of HIV ${ }^{14}$ anticancer compounds, ${ }^{15}$ cholesteryl ester transfer protein inhibitors, ${ }^{16}$ antiinflammatory compounds, ${ }^{17}$ antitumor agents, ${ }^{18}$ and also as agrochemicals. ${ }^{19}$ However, enantioselective approaches to the synthesis of chiral dihydroquinoxalin-2-ones are scarce and limited to catalytic asymmetric hydrogenations of quinoxalinones. ${ }^{20,21}$ In view of the few examples of the catalytic asymmetric methodologies for the synthesis of such compounds, we envisioned that the corresponding quinoxalin-2-one 
generated under mild conditions from 3,4-dihydroquinoxalin-2one by a photocatalyzed oxidation, might react with carbonyl compounds using asymmetric enamine catalysis giving a Mannich product. Hence, continuing with our interest on the synthesis of 1,4-dihydroquinoxalinones ${ }^{22}$ and the photoredox functionalization of cyclic amines, ${ }^{23}$ we described the development of a dual organocatalyst strategy for the enantioselective oxidative alkylation of dihydroquinoxalinones with ketones through an asymmetric Mannich reaction (Scheme 1).

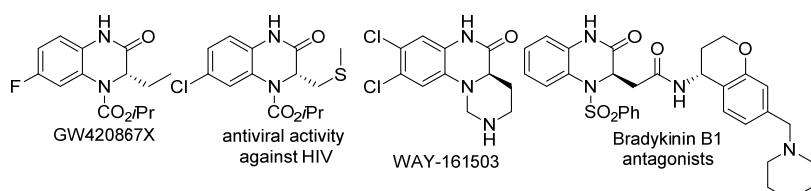

Figure 1. Selected bioactive chiral dihydroquinoxalinones.

The enantioselective Mannich reaction between 3,4dihydroquinoxalin-2-one (1a) and acetone (2a) using (S)proline as organocatalyst was selected as the model reaction (Table 1). The initial reaction using $1 \mathrm{~mol} \%$ of $\operatorname{Ir}($ ppy) 3 under irradiation of $5 \mathrm{~W}$ white LEDs, gave the corresponding chiral Mannich product 3aa with an excellent $99 \%$ ee, but low yield (34\%, entry 1). In order to avoid possible side reactions in our system, ${ }^{24}$ we decided to attempt the activation of the substrates separately. ${ }^{13}$ Accordingly, dihydroquinoxalin-2-one (1a) and 1 mol $\%$ of $\operatorname{Ir}$ (ppy) 3 were dissolved in $1 \mathrm{~mL}$ of $\mathrm{CH}_{3} \mathrm{CN}$ and stirred under irradiation of $5 \mathrm{~W}$ white LEDs and air atmosphere. After 2 days, the starting material 1a was consumed and the formation of the cyclic imine quinoxalin-2-one was observed. Then, acetone $\mathbf{2 a}(1 \mathrm{~mL})$ and $(S)$-proline $(20 \mathrm{~mol} \%)$ were added to the reaction mixture and stirred $80 \mathrm{~h}$ under darkness, in order to avoid the over oxidation products. The desired product 3aa was isolated with the same enantiomeric excess ( $99 \%$ ee), but much better yield ( $77 \%$, entry 2$)$.

Next, we evaluated the light sources (entries 2-4), observing that the oxidation was much faster, only 4 hours, under blue LEDs irradiation although the yield was lower (59\%) (entry 4). Other photocatalysts $\left(\mathrm{Ru}(\mathrm{bpy})_{3} \mathrm{Cl}_{2}\right.$, Fukuzumi photocatalyst and Eosin Y) were evaluated (entries 5-7), obtaining similar reaction times, yields and enantioselectivities. In order to develop a more cost-effective and green protocol, we decided to continue the optimization using Eosin $\mathrm{Y}$ as photocatalyst. Then, different solvents such as toluene, $\mathrm{CHCl}_{3}$, DMSO and DMF were evaluated (entries 8-11). In toluene and $\mathrm{CHCl}_{3}$, the oxidation step was very slow, while with DMSO and DMF, the oxidation step was similar than $\mathrm{CH}_{3} \mathrm{CN}$. In view that the enantioselective Mannich reaction was faster in DMF (2 days, entry 11) we continue the optimization with this solvent. Lowering the photocatalyst to $2 \mathrm{~mol} \%$ was beneficial for both steps, obtaining product 3aa with $74 \%$ yield and $99 \%$ ee after 21 hours (entry 12). Decreasing the amount of acetone to 10 equivalents (entry 13) was detrimental for the speed of the asymmetric Mannich reaction (3 days), and product 3aa was isolated with $82 \%$ yield and $96 \%$ ee. Finally, several control experiments were carried out. When the reaction was carried out under darkness (entry 14), we did not observe the oxidation of dihydroquinoxalin-2-one 1a to quinoxalin-2-one after 5 days. While the reaction performed without catalyst (entry 15), gave the corresponding oxidation of dihydroquinoxalin-2-one, but very slowly (102 hours). The subsequent addition of acetone and $(S)$-proline, led the formation of product 3aa with $73 \%$ yield and $99 \%$ ee. Moreover, we performed the enantioselectove Mannich reaction using the imine (quinoxalin$2(1 H)$-one) as electrophile (entry 16 ) obtaining good yield and excellent enantioselectivity ( $99 \%$ ee).

Table 1. Optimization of the reaction conditions ${ }^{\mathrm{a}}$

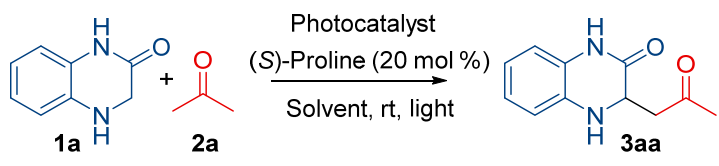

\begin{tabular}{|c|c|c|c|c|c|c|}
\hline Entry & PC (\%) & Solvent & $\mathrm{t}_{1}(\mathrm{~h})$ & $t_{2}(h)$ & Yield $(\%)^{b}$ & ee $(\%)^{c}$ \\
\hline $1^{\mathrm{d}}$ & $\operatorname{Ir}(\text { ppy })_{3}(1 \%)$ & $\mathrm{MeCN}$ & 74 & - & 34 & 99 \\
\hline 2 & $\operatorname{Ir}(\text { ppy })_{3}(1 \%)$ & $\mathrm{MeCN}$ & 48 & 80 & 77 & 99 \\
\hline $3 e$ & $\operatorname{Ir}(\text { ppy })_{3}(1 \%)$ & $\mathrm{MeCN}$ & 24 & 79 & 66 & 99 \\
\hline $4^{\mathrm{f}}$ & $\operatorname{Ir}(\text { ppy })_{3}(1 \%)$ & $\mathrm{MeCN}$ & 4 & 68 & 59 & 99 \\
\hline $5^{\mathrm{f}}$ & $\mathrm{Ru}(\mathrm{bpy})_{3} \mathrm{Cl}_{2}(1 \%)$ & $\mathrm{MeCN}$ & 6 & 70 & 66 & 99 \\
\hline $6^{\mathrm{f}}$ & $\begin{array}{c}\text { Fukuzumi photo- } \\
\text { cat. }(5 \%)\end{array}$ & $\mathrm{MeCN}$ & 9 & 70 & 82 & 97 \\
\hline $7^{\mathrm{f}}$ & Eosin Y $(5 \%)$ & $\mathrm{MeCN}$ & 9 & 86 & 63 & 98 \\
\hline $8^{f}$ & Eosin Y $(5 \%)$ & toluene & 78 & 72 & 33 & 92 \\
\hline $9^{f}$ & Eosin Y $(5 \%)$ & $\mathrm{CHCl}_{3}$ & 78 & 72 & 86 & 98 \\
\hline $10^{\mathrm{f}}$ & Eosin Y $(5 \%)$ & DMSO & 9 & 86 & 63 & 84 \\
\hline $11^{\mathrm{f}}$ & Eosin $Y(5 \%)$ & DMF & 8 & 46 & 75 & 98 \\
\hline $12^{\mathrm{f}}$ & Eosin $Y(2 \%)$ & DMF & 7 & 21 & 74 & 99 \\
\hline $13^{\mathrm{f}, \mathrm{g}}$ & Eosin Y $(2 \%)$ & DMF & 7 & 65 & 82 & 96 \\
\hline $14^{\mathrm{h}}$ & Eosin Y $(5 \%)$ & DMF & 120 & - & - & - \\
\hline 15 & - & DMF & 102 & 21 & 73 & 99 \\
\hline $16^{\mathrm{i}}$ & - & DMF & - & 15 & 95 & 99 \\
\hline
\end{tabular}

${ }^{a}$ Reaction conditions: A stepwise procedure where 1a $(0.2$ $\mathrm{mmol}$ ) and photocatalyst (X mol\%) were dissolved in $1 \mathrm{~mL}$ of solvent and stirred at $\mathrm{rt}$ under air atmosphere and irradiation of $5 \mathrm{~W}$ white LEDs; upon consumption of the starting material, $2 \mathbf{a}(1 \mathrm{~mL})$ and $(S)$-proline $(20 \mathrm{~mol} \%)$ were added and stirred under darkness. ${ }^{b}$ Yield after purification by column chromatography. ${ }^{c}$ The enantiomeric excess was determined by HPLC analysis. ${ }^{d}$ Reaction conditions: 1a $(0.2 \mathrm{mmol}), 2 \mathrm{2a}(1 \mathrm{~mL}), \operatorname{Ir}(\mathrm{ppy})_{3}(1 \mathrm{~mol} \%)$, (S)proline $(20 \mathrm{~mol} \%)$ in $1 \mathrm{~mL}$ of $\mathrm{MeCN}$ at $\mathrm{rt}$ under air atmosphere and irradiation of $5 \mathrm{~W}$ white LEDs. ${ }^{e}$ Under irradiation of a $11 \mathrm{~W}$ fluorescent bulb light. $f$ Under irradiation of blue LEDs. ${ }^{g} 10$ equivalents of 2a were used. ${ }^{h}$ Reaction performed under darkness. ${ }^{i}$ The Mannich reaction was performed using quinoxalin-2(1H)-one as electrophile.

Once we had the optimized reaction conditions (entry 12), we evaluated the scope of the enantioselective oxidative Mannich reaction, as is shown in the Scheme 2. First we evaluated the effect of the protecting group at the nitrogen of the amide of dihydroquinoxalin-2-one 1 . The reaction tolerates several groups at the nitrogen atom, such as methyl, benzyl, allyl or $\mathrm{CH}_{2} \mathrm{CO}_{2} \mathrm{Me}$, affording the corresponding chiral quinoxalines 3 with good yields and excellent enantioselectivities. These results are remarkable, because only the oxidation of the endocyclic $\mathrm{CH}_{2}$ was observed (3ba-3ea). 3,4dihydroquinoxalin-2-one (1) bearing electron-donating (Me, $\mathrm{OMe})$ or electron-withdrawing $\left(\mathrm{CF}_{3}, \mathrm{~F}, \mathrm{CO}_{2} \mathrm{H}\right)$ groups on the aromatic ring furnished the corresponding chiral ketones $\mathbf{3}$ in good yields (58-93\%) and excellent enantioselectivities (97-99 $\%$ ee), regardless of the position or the electronic character of the substituents (3fa-3ma). Moreover, disubstituted 3,4dihydroquinoxalin-2-one can be also used obtaining the corresponding chiral quinoxalin-2-ones 3na and 3oa with excellent results both in yield and enantiomeric excess. We next explored the asymmetric Mannich reaction with other ketones such as butan-2-one $\mathbf{2 b}$, 4-methylpentan-2-one $\mathbf{2 c}$ or undecan2-one 2d, that afford the corresponding chiral products with excellent regio- and enantioselectivities, although with moderate yields (42-55\%). Meanwhile, cyclic ketones such as 
cyclohexanone and cyclopentanone were examined, affording the corresponding chiral Mannich products with excellent yields, but low diastereo- and enantioselectivities. ${ }^{25}$ Finally, the reaction tolerates functionalized ketones such 1hydroxypropan-2-one or 1,1-dimethoxypropan-2-one, obtaining products 3ag and 3ah with excellent results. Interestingly, the 1-hydroxypropan-2-one gave exclusively the branched product, while the 1,1-dimethoxypropan-2-one gave only the linear product. This is usual for proline catalyzed aldol $^{26}$ or Mannich ${ }^{9}$ reactions, where the less substituted enamine is formed. In contrast to 2-butanone or 1,1dimethoxypropan-2-one, the regioselectivity of enamine formation in the case of the hydroxyacetone is controlled by the $\pi$-donating $\mathrm{OH}$ group, which interacts with the $\pi^{*}$-orbital of the $\mathrm{C}=\mathrm{C}$ bond thereby stabilizing the hydroxyl enamine. ${ }^{27}$

Scheme 2. Enantioselective Photooxidative Mannich Reaction.

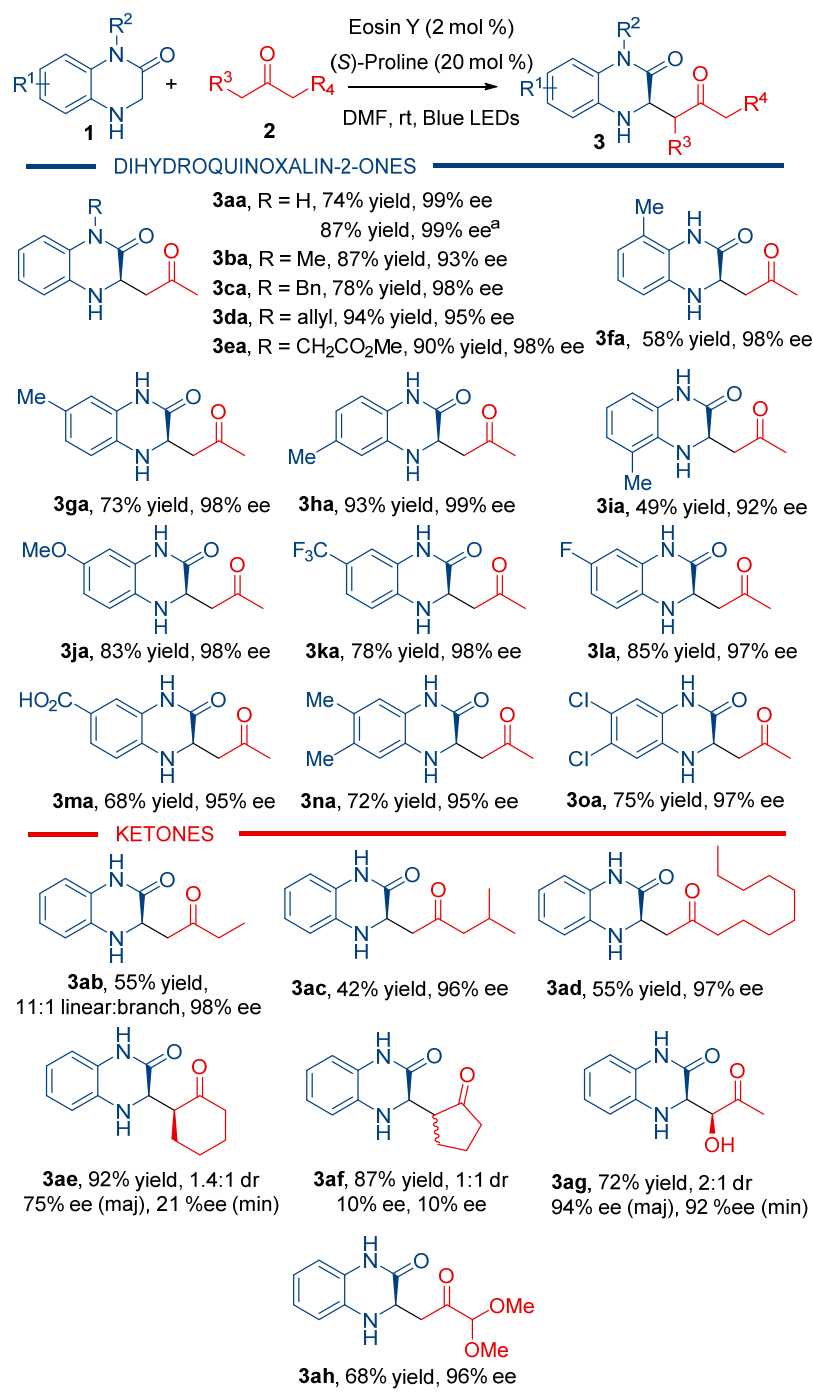

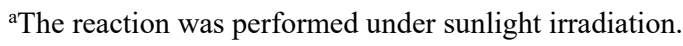

Gratifyingly, the practicability and scalability of this protocol were successfully demonstrated by performing the enantioselective oxidative Mannich reaction at $5 \mathrm{mmol}$ scale using sun light and only $0.5 \mathrm{~mol} \%$ of Eosin Y (Scheme 3 ). Under these conditions, the results were similar to those obtained on small scale (67\% yield and $99 \%$ ee).
Scheme $3.5 \mathrm{mmol}$ reaction scale using sun light as source of irradiation.<smiles></smiles>

1a, $5 \mathrm{mmol}, 740 \mathrm{mg}$

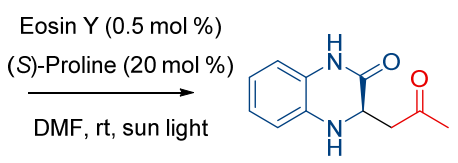

3aa, $67 \%$ yield, $99 \%$ ee
To elucidate the mechanism of the reaction, control experiments were conducted. The addition of TEMPO, a radical scavenger, inhibited the oxidation of $\mathbf{1}$, as well as when the reaction was runned in the absence of oxygen. In addition, we performed Stern-Volmer quenching experiment for the exicited Eosin Y photocatalyst with amine $1\left(\mathrm{~K}_{\mathrm{sV}}=79 \mathrm{M}^{-1}\right)$, suggesting that the reaction might proceed through an reductive quenching pathway. ${ }^{28}$ Therefore, under the irradiation of visible-light and in the presence of Eosin $\mathrm{Y}$ and oxygen, dihydroquinoxalin-2one $\mathbf{1}$ is oxidized to quinoxalin-2(1H)-one, which reacts with the corresponding ketone affording the Mannich product 3 . On the basis of the absolute configuration of $\mathbf{3 a a},{ }^{29,30}$ we propose a plausible mechanism for the enantioselective oxidative Mannich reaction as is shown in the Scheme 4. (S)-Proline reacts with acetone to form an enamine, that attacks the $R e$ face of the cyclic imine. The enantioselectivity is further controlled by hydrogen bonding between the proline carboxylic acid group and the cyclic imine. ${ }^{9,10}$

\section{Scheme 4. Plausible stereochemical pathway.}

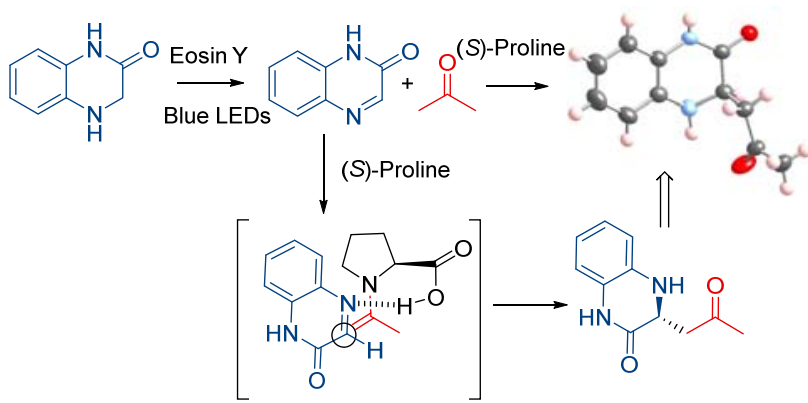

In summary, we have developed a photooxidative enantioselective Mannich reaction of 3,4-dihydroquinoxalin-2-one derivatives with several ketones using visible-light organophotoredox and enamine catalysis. ${ }^{31}$ The corresponding chiral quinoxaline products were obtained with good yields and excellent enantioselectivities under very mild conditions. The reaction is scalable to $5 \mathrm{mmol}$ scale using sun light. Our methodology shows a successfully combination of visible-light organophotoredox and enantioselective organocatalysis, in order to obtain interesting quinoxalinone derivatives.

\section{ASSOCIATED CONTENT}

\section{Supporting Information}

The Supporting Information is available free of charge on the ACS Publications website. Complete experimental procedures and characterization of new products, ${ }^{1} \mathrm{H}$ and ${ }^{13} \mathrm{C}$ NMR spectra and HPLC traces for all compounds.

\section{AUTHOR INFORMATION}

\section{Corresponding Author}

*E-mail: jose.r.pedro@uv.es; carlos.vila@uv.es. 


\section{ACKNOWLEDGMENT}

Financial support from the Agencia Estatal de Investigación (AEI, Spanish Government) and Fondo Europeo de Desarrollo Regional (FEDER, European Union) (CTQ2017-84900-P) is acknowledged. J.R-B thanks the Ministerio de Ciencia, Innovación y Universidades for a FPU predoctoral contract and C.V. thanks the Agencia Estatal de Investigación (AEI, Spanish Government) for RyC contract (RYC-2016-20187). Access to NMR, MS and X-ray facilities from the Servei Central de Suport a la Investigació Experimental (SCSIE)-UV is also acknowledged.

\section{REFERENCES} 2013 .

1) König, B. Chemical Photocatalysis; De Gruyter, Berlin/Boston,

(2) (a) Ciamician, G. Science, 1912, 36, 385. (b) Albani, A.; Fagnoni, M. Green Chem. 2004, 6, 1. (c) Yoon, T. Acc. Chem. Res. 2016, 49, 2307. (d) Narayanam, J. M. R.; Stephenson, C. R. J. Chem. Soc. Rev. 2011, 40, 102. (e) Prier, C. K.; Rankic, D. A.; MacMillan, D. W. C. Chem. Rev. 2013, 113, 5322. (f) Romero, N. A.; Nicewicz, D. A. Chem. Rev. 2016, 116, 10075. (g) Hoffmann, N. ChemSusChem, 2012, 5, 352 .

(3) (a) Davies, N. M.; Teng, X.-W.; Adv. Pharm., 2003, 1, 242. (b) Maher, T. J.; Johnson, D. A. Drug Dev. Res., 1991, 24, 149. (c) Brandt, J. R.; Salerno, F.; Fuchter, M. J. Nat. Rev. Chem. 2017, 1, 0045. (d) Brooks, H. W.; Guida, C. W.; Daniel, G. K. Curr. Top. Med. Chem. 2011, 11, 760. (e) Leitereg, T. J.; Guadagni, D. G.; Harris, J.; Mon T. R.; Teranishi, R. J. Agr. Food Chem. 1971, 19, 785. (f) Kane-Maguire, L. A. P.; Wallace, G. G. Chem. Soc. Rev. 2010, 39, 2545.

(4) (a) Jacobsen, E. N.; Pfaltz, A.; Yamamoto, H. Comprehensive Asymmetric Catalysis, Springer, Berlin, 1999. (b) Blaser, H.-U.; Schmidt, E. Asymmetric Catalysis on Industrial Scale: Challenges, Approaches and Solutions, Wiley-VCH, Weinheim, 2004. (c) Ojima, I. Catalytic Asymmetric Synthesis, John Wiley \& Sons, New Jersey, 2010; (d) Walsh, P. J.; Kozlowski, M. C. Fundamentals of Asymmetric Catalysis, University Science Books, Sausalito, 2008.

(5) (a) Meggers, E. Chem. Commun., 2015, 51, 3290. (b) Wang, C.; Lu, L. Org. Chem Front. 2015, 2, 179. (c) Silvi, M. P. Melchiorre, P. Nature 2018, 554, 41.

(6) (a) Zou, Y.-Q.; Hörmann, F. M.; Bach, T. Chem. Soc. Rev. 2018, 47, 278. For the seminal work, see: (b) Nicewicz, D. A.; MacMillan, D. W. C. Science, 2008, 322, 77.

(7) (a) Nakajima, K.; Miyake, Y.; Nishibayashi, Y. Acc. Chem. Res., 2016, 49, 1946. (b) Shi, L.; Xia, W. Chem. Soc. Rev., 2012, 41, 7687. For selected enantioselective reactions, see: (c) DiRocco, D. A.; Rovis, T. J. Am. Chem. Soc., 2012, 134, 8094. (d) Bergonzini, G.; Schindler, C. S.; Wallentin, C.-J.; Jacobsen, E. N.; Stephenson, C. R. J. Chem. Sci., 2014, 5, 112. (e) Perepichka, I.; Kundu, S.; Hearne, Z.; Li, C.-J. Org. Biomol. Chem., 2015, 13, 447. (f) Wei, G.; Zhang, C.; Bureš, F.; Ye, X.; Tan, C.-H.; Jiang, Z. ACS Catal., 2016, 6, 3708. (g) Uraguchi, D.; Kinoshita, N.; Kizu, T.; Ooi, T. J. Am. Chem. Soc., 2015, 137, 13768. (h) Murphy, J. J.; Bastida, D.; Paria, S.; Fagnoni, M.; Melchiorre, P. Nature 2016, 532, 218. (i) Wang, C.; Qin, J.; Shen, X.; Riedel, R.; Harms, K.; Meggers, E. Angew. Chem. Int. Ed. 2016, 55, 685.

(8) Nugent, T.C. Chiral Amine Synthesis: Methods, Developments and Applications, Wiley-VCH, Weinheim, 2010.

(9) List, B. J. Am. Chem. Soc. 2000, 122, 9336

(10) (a) Córdova, A. Acc. Chem. Res. 2004, 37, 102. (b) Ting, A.; Schaus, S. E. Eur. J. Org. Chem. 2007, 5797. (c) Verkade, J. M. M.; van Hemert, L. J. C.; Quaedflieg, P. J. L. M.; Rutjes, F. P. J. T. Chem. Soc. Rev., 2008, 37, 29. (d) Arend, M.; Westermann, B. Risch, N. Angew. Chem. Int. Ed. 1998, 37, 1044.

(11) (a) Zhang, G.; Zhang, Y.; Wang, R. Angew. Chem. Int. Ed. 2011, 50, 10429. (b) Zhang, J.; Tiwari, B.; Xing, C.; Chen, X.; Chi, Y. R. Angew. Chem. Int. Ed. 2012, 51, 3649. (c) Zhang, G.; Ma, Y.; Wang,
S.; Kong, W.; Wang, R. Chem. Sci. 2013, 4, 2645. (d) Tan, Y.; Yuan, W.; Gong, L.; Meggers, E. Angew. Chem. Int. Ed. 2015, 54, 13045.

(12) Yang, Q.; Zhang, L.; Ye, C.; Luo, S.; Wu, L.-Z.; Tung, C.-H. Angew. Chem. Int. Ed. 2017, 56, 3694.

(13) Hou, H.; Zhu, S.; Atodiresei, I.; Rueping, M. Eur. J. Org. Chem. 2018, 1277 .

(14) (a) Rösner, M.; Billhardt-Troughton, U.-M.; Kirsh, R.; Kleim, J.-P.; Meichsner, C.; Riess, G.; Winkler, I. U.S. Patent 5, 723, 461, 1998. (b) Abraham, C. J.; Paull, D. H.; Scerba, M. T.; Grebinski, J. W.; Lectka, T. J. Am. Chem. Soc. 2006, 128, 13370. (c) Ren, J.; Nichols, C. E.; Chamberlain, P. P.; Weaver, K. L.; Short, S. A.; Chan, J. H.; Kleim, J.-P.; Stammers, D. K. J. Med. Chem., 2007, 50, 2301. (d) Cass, L. M.; Moore, K. H. P.; Dallow, N. S.; Jones, A. E.; Sisson, J. R.; Prince, W. T. J. Clin. Pharmacol., 2001, 41, 528 .

(15) Tanimori, S.; Nishimira, T.; Kirihata, M. Bioorg. Med. Chem. Lett. 2009, 19, 4119.

(16) Eary, C. T.; Jones, Z. S.; Groneberg, R. D.; Burgess, L. E.; Mareska, D. A.; Drew, M. D.; Blake, J. F.; Laird, E. R.; Balachari, D.; O'Sullivan, M.; Allen, A.; Marsh, V. Bioorg. Med. Chem. Lett., 2007, 17, 2608.

(17) Chen, J. J. Qian, W.; Biswas, K.; Viswanadhan, V. N.; Askew, B. C.; Hitchcock, S.; Hungate, R. W.; Arik, L.; Johnson, E. Bioorg. Med. Chem. Lett., 2008, 18, 4477.

(18) Abu Shuheil, M. Y.; Hassuneh, M. R.; Al-Hiari, Y. M.; Qaisi, A. M.; El-Abadelah, M. M. Heterocycles 2007, 71, 2155.

(19) (a) Carter, G. A.; Clark, T.; James, C. S.; Loeffler, R. S. T. Pest Manage. Sci. 1983, 14, 135. (b) Sakata,G.; Makino, K.; Kurasawa, Y. Heterocycles 1988, 27, 2481.

(20) (a) Rueping, M.; Tato, F.; Schoepke, F. R. Chem. Eur. J., 2010, 16, 2688. (b) Núñez-Rico, J. L.; Vidal-Ferran, A. Org. Lett., 2013, 15 , 2066. (c) Shi, F.; Tan, W.; Zhang, H.-H.; Li, M.; Ye, Q.; Ma, G.-H.; Tu, S.-J.; Li, G. Adv. Synth. Catal., 2013, 355, 3715. (d) Chen, M.-W.; Deng, Z.; Yang, Q.; Huang, J.; Peng, Y. Org. Chem. Front. 2019, 6, 746.

(21) Zhang, X.; Xu, B.; Xu, M.-H. Org. Chem. Front. 2016, 3, 944

(22) De Munck, L.; Vila, C.; Pons, C.; Pedro, J. R. Synthesis, 2017, $49,2683$.

(23) Rostoll-Berenguer, J.; Blay, G.; Pedro, J. R.; Vila, C. Catalysts, 2018, 8, 653 .

(24) We observed the oxidation product 4.

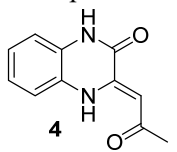

(25) When cycloheptanone was used as nucleophile the reaction was very slow and the product was observed with very low conversion after several days.

(26) Sakthivel, K.; Notz, W.; Bui, T.; Barbas III, C. F. J. Am. Chem. Soc. 2001, 123, 5260

(27) (a) Lin, J.-F.; Wu, C.-C.; Lien, M.-H. J. Phys. Chem. 1995, 99, 16903. (b) Hoffmann, T.; Zhong, G.; List, B.; Shabat, D.; Anderson, J.; Gramatikova, S.; Lerner, R. A.; Barbas III, C. F., J. Am. Chem. Soc. $1998,120,2768$

(28) See supporting information for further details.

(29) CCDC 1922649 (3aa) contains the supplementary crystallographic data for this paper. These data can be obtained free of charge from The Cambridge Crystallographic Data Centre via www.ccdc.cam.ac.uk/data request/cif.

(30) A crystal structure of a similar compound, racemic ethyl 2-(3oxo-1,2,3,4-tetrahydroquinoxalin-2-yl)acetate, have been published: Abad, N.; Sebhaoui, J.; El Bakri, Y.; Ramli, Y.; Essassi, E. M.; Mague, J. T. IUCrData, 2018, 3, x180596.

(31) $n$-Butanal was tested as nucleophile under the optimized reaction conditions, although the corresponding product was obtained with moderate yield (51\%) without stereochemical control $(1: 1 \mathrm{dr}, 0 \%$ ee: $0 \%$ ee). 